\title{
KAJIAN LITERATUR IMPLEMENTASI PROGRAM BILINGUAL PADA PENDIDIKAN BERBASIS PESANTREN
}

\author{
Alifia Fitranti \\ Universitas Negeri Surabaya \\ Email: alifiafitranti.20006@mhs.unesa.ac.id
}

\begin{abstract}
As the development of times or often called globalization, many parties make many changes to adapt it. also in the education sector which has to adapt a lot in order to be able to compete and achieve the goals of Indonesian education. In global competition, education in Indonesia is expected to be able to compete with various developed countries, namely improving the quality of education by mastering international languages and applying it in a learning process. However, not only formal schools can do this, but also Islamic boarding schools as part of the education system in Indonesia have also made many changes so that pesantren become more modern by implementing bilingual programs into the teaching process. The purpose of this study is to produce issues related to the implementation of bilingual programs in pesantrenbased education by reviewing 10 journals related to bilingual programs in Islamic boarding schools using the literature study research method. These results include: 1) Islamic boarding schools as part of the National Education System are expected to support Indonesia's educational goals by following the era of globalization, 2) Islamic boarding schools may apply as a national education system that is able to keep up with the times and compete globally with bilingual programs in the learning process, 3) With the modernization of pesantren, it does not change the characteristics of pesantren as educational institutions that adhere to Islamic religious knowledge, 4) Bilingual programs can be implemented in pesantren because they can improve the quality of education in accordance with the expectations of parents. Therefore, it can be said that pesantren can follow the development of education and be able to participate in the advancement of Indonesian education by implementing bilingual programs as a form of learning.
\end{abstract}

Keywords: Bilingual Program, Education, Pesantren

\begin{abstract}
Abstrak
Seiring dengan perkembangan zaman atau sering disebut globalisasi membuat banyak pihak melakukan banyak perubahan untuk menyesuaikannya. Begitu juga dalam sektor pendidikan yang harus banyak menyesuaikan agar mampu bersaing dan mencapai tujuan pendidikan Indonesia. Dalam persaingan secara global, pendidikan di Indonesia diharapkan mampu bersaing dengan beragam negara maju yaitu meningkatkan kualitas pendidikan dengan menguasai bahasa internasional dan diterapkan dalam suatu proses
\end{abstract}


pembelajaran. Namun, tidak hanya sekolah formal yang dapat melakukan tetapi juga lembaga pesantren sebagai bagian dari sistem Pendidikan di Indonesia juga banyak melakukan perubahan agar pesantren menjadi lebih modern dengan menerapkan program bilingual ke dalam proses pengajaran. Tujuan dari penelitian ini yaitu untuk menghasilkan hal-hal terkait dengan implementasi program bilingual pada pendidikan berbasis pesantren dengan mengkaji 10 jurnal terkait program bilingual dalam lembaga pesantren menggunakan metode penelitian studi literatur. Hasil tersebut antara lain : 1) Pesantren sebagai bagian dari Sistem Pendidikan Nasional diharapkan turut membangun tujuan pendidikan Indonesia dengan mengikuti perkembangan era globalisasi, 2) Pesantren berpotensi sebagai sistem pendidikan nasional yang mampu mengikuti perkembangan zaman dan bersaing secara global dengan menerapkan program bilingual pada proses pembelajaran, 3) Dengan adanya modernisasi pesantren tidak mengubah karakteristik pesantren sebagai lembaga pendidikan yang berpegang pada ilmu agama Islam, 4) Program bilingual dapat dengan baik diterapkan di pesantren karena dapat meningkatkan mutu pendidikan yang sesuai dengan harapan para orangtua. Oleh karena itu dapat disimpulkan bahwa pesantren dapat mengikuti perkembangan pendidikan dan mampu turut serta dalam kemajuan pendidikan Indonesia dengan mengimplementasikan program bilingual sebagai salah satu bentuk pembelajaran.

Kata Kunci : program bilingual, pendidikan, pesantren

\section{Pendahuluan}

Perkembangan zaman atau sering disebut globalisasi untuk saat ini memang tidak dapat dihindari, berbagai sektor mulai dari industri hingga Pendidikan pun telah melakukan perubahan sedemikian rupa untuk mengimbangi perubahan zaman secara global agar tidak tertinggal dengan negara dan bangsa lain. Dalam dunia pendidikan terutama di Indonesia telah banyak mengalami perubahan untuk menyesuaikan kurikulum yang sesuai dengan adanya perubahan zaman ini. Hingga saat ini kurikulum pendidikan Indonesia tercatat telah diubah sebanyak $10 \mathrm{kali}$, dan yang terakhir diterapkan hingga saat ini adalah kurikulum 2013 (K13) ${ }^{1}$. Perubahan kurikulum dalam pendidikan bukanlah hal yang buruk melainkan bentuk rasa ingin maju dalam sektor pendidikan. Hal ini dikarenakan kualitas pendidikan Indonesia masih tergolong rendah berdasarkan laporan dari HDI (Human Development Index)2. Oleh karena itu,

\footnotetext{
${ }^{1}$ Alhamuddin, "Sejarah Kurikulum Di Indonesia," Nur El-Islam 1, no. 2 (2014): 48-58.

${ }^{2}$ Connie Chairunnisa, Manajemen Pendidikan Dalam Multi Perspektif(Jakarta: Rajawali Press, 2016).
} 
banyak upaya yang dilakukan oleh pemerintah yang berkoordinasi dengan setiap satuan pendidikan untuk meningkatkan kualitas pendidikan.

Pesantren merupakan lembaga pendidikan Islam tertua di Indonesia yang berperan penting dalam perkembangan ilmu agama Islam yang memiliki akar kuat untuk menjaga kelestariannya. Namun lembaga pesantren masih dikelola dengan cara tradisional dalam hal manajemen lembaga, sarana prasarana yang kurang memadai dan kurikulum yang masih berorientasi pada life skills dan masyarakat. Hal tersebut dapat menjadi tantangan yang berat di masa depan, kemampuan santri dalam ilmu agama tidak cukup tetapi harus ditunjang dengan kemampuan dan keahlian lain ${ }^{3}$.

Upaya yang dilakukan untuk meningkatkan kualitas pendidikan sangat banyak, baik program pemerintah maupun pengembangan masingmasing satuan pendidikan atau lembaga. Salah satunya yaitu adanya wujud sekolah yang menggunakan program bilingual pada pembelajaran yang dilakukan yaitu Rintisan Sekolah Berstandar Internasional (RSBI) ${ }^{4}$. Program bilingual khususnya bahasa Inggris sangat penting dilaksanakan oleh beberapa satuan pendidikan karena bahasa Inggris dianggap sebagai bahasa internasional yang harus dipelajari sedini mungkin untuk menciptakan suatu kebiasaan ${ }^{5}$. Selain itu program bilingual tidak hanya dapat dilaksanakan pada sekolah atau lembaga melainkan juga diterapkan pada pesantren-pesantren yang ada di Indonesia karena pesantren diharapkan mampu melakukan pembaharuan sistem pendidikan dengan mengikuti zaman dengan menyediakan pendidikan berkarakter, berkualitas dalam iman, ilmu dan amal shaleh ${ }^{6}$. Pesantren sebagai lembaga pendidikan tertua di Indonesia dengan karakter yang kuat diharapkan

\footnotetext{
${ }^{3}$ usman muhammad Idris, "Pesantren Sebagai Lembaga Pendidikan Islam," Al Hikmah XIV, no. 1 (2013): 101-19.

${ }^{4}$ Balitbang Kemdiknas, "Kajian Terhadap Keberadaan Dan Pendanaan Rintisan Sekolah Bertaraf Internasional ( RSBI )," Jurnal Dikbud, 2006, 373-82.

${ }^{5}$ Rismareni Pransiska, "Kajian Program Bilingual Terhadap Perkembangan Kognitif Anak Usia Dini," Edukasi Journal 10, no. 2 (2018): 167-78, https://doi.org/10.31603/edukasi.v10i2.2409.

${ }^{6}$ Imam Syafe'i, "Pondok Pesantren Yang Melembaga Di Masyaraka Satu Lembaga Pendidikan Islam Tertua Di Indonesia . Awal Kehadiran Boarding School Bersifat Tradisional Untuk Mendalami Ilmu-Ilmu Agama Isl," Al-Tadzkiyyah: Jurnal Pendidikan Islam 8, no. I (2017): 61-82.
} 
mampu melihat perkembangan pendidikan di era masa kini agar pesantren mampu menjadi lembaga pendidikan yang seimbang antara pendidikan formal dan pendidikan islam sebagai lembaga tertua di Indonesia, tidak hanya lembaga pendidikan formal yang selalu mengikuti perubahan zaman tetapi pesantren juga selalu mengalami perubahan yang dinamis dalam sistem pendidikannya ${ }^{7}$. Walaupun semakin banyaknya lembaga pendidikan formal tetapi pesantren tetap dapat bertahan di tengah persaingan pendidikan karena dianggap mampu untuk menyerap kebudayaa luar namun tetap berpegang teguh pada ajaran agama Islam.

Dalam artikel ini, akan dibahas mengenai program bilingual yang telah dilakukan oleh beberapa lembaga serta proses pendidikan yang ada di pesantren. Tujuan adanya artikel ini yaitu dapat memberikan informasi mendalam terkait implementasi program bilingual dalam proses pembelajaran di sekolah berbasis pesantren.

\section{Program Bilingual}

Program bilingual adalah penerapan pembelajaran dalam bahasa selain bahasa sehari-hari siswa yaitu bahasa Inggris9. Pengertian lain program bilingual adalah proses belajar mengajar di dalam kelas yang menggunakan sekurang-kurangnya 2 bahasa ${ }^{10}$. Bahasa yang dimaksud adalah berkaitan dengan bahasa utama dan bahasa yang ingin diajarkan dalam pembelajaran. Program bilingual banyak diterapkan di banyak negara terutama bahasa Inggris karena bahasa Inggris digunakan sebagai bahasa internasional untuk berkomunikasi dalam berbagai kepentingan seperti pendidikan, bisnis, dan lain sebagainya. Dalam rancangan penelitian ini, bahasa utama yang digunakan dalam kelas adalah bahasa Indonesia

\footnotetext{
7 Alaika M Bagus Kurnia PS, "Problematika Pesantren Sebagai Lembaga Pendidikan Islam Di Indonesia," Tawazun: Jurnal Pendidikan Islam 12, no. 2 (2019): 5-10, https://doi.org/10.32832/tawazun.v12i2.2554.

8 Mohammad Hasan, "Perkembangan Pendidikan Pesantren Di Indonesia," TADRIS: Jurnal Pendidikan Islam 10, no. 1 (2015): 55, https://doi.org/10.19105/jpi.v10i1.638.

${ }^{9}$ Dwi Ima, “Types of Bilingual Education," Bahasa Lingua Scientia 5, no. 2 (2013): 212-26.

${ }^{10}$ Santoso and Pirman, Bilingual Education Program (Jakarta: Prenadamedia Group, 2015).
} 
dan bahasa lain yang digunakan sebagai tujuan utama program bilingual adalah bahasa Inggris.

Bilingual atau dua bahasa diartikan sebagai kemampuan seseorang menggunakan 2 bahasa baik dalam situasi formal ataupun non formal. Kemampuan menggunakan bahasa alternatif terlihat pada saat situasi formal seperti pendidikan atau sosial. Kemampuan dalam 2 bahasa dikategorikan menjadi beberapa bagian antara lain ${ }^{11}$ :

a. Balanced bilinguals : dalam tingkatan ini seseorang telah menguasai 2 bahasa secara fasih namun dapat mengontrol bahasa utama yang biasa digunakan dengan bahasa alternatif yang menjadi keahliannya.

b. Dominant bilinguals : Tingkatan ini menunjukkan seseorang yang memiliki kemampuan menguasai 2 bahasa tetapi hanya menunjukkan 1 bahasa yang dikuasai saja. Contohnya guru yang keseharian mengajar menggunakan bahasa Inggris akan menggunakan bahasa tersebut sepanjang hari namun apabila guru tersebut berdiskusi dengan orang italia maka ia akan berdiskusi dengan bahasa lain yang ia kuasai sesuai dengan lawan diskusinya.

c. Passive or recessive bilinguals : seseorang yang memiliki kemampuan dalam 2 bahasa tetapi bahasa tersebut hilang karena tidak digunakan lagi sehingga disebut kemampuan yang pasif. Contohnya seorang WNI yang lama tinggal dan menetap di Amerika dengan bahasa sehari-hari adalah bahasa Inggris maka ia pasif di bahasa Indonesia.

d. Semilingual or limited bilinguals : beberapa ciri dari tingkat kemampuan bilingual ini adalah kosakata yang sedikit dan grammar yang tidak tepat, kaku Ketika berbicara dan susunan kata yang terbatas, dan kesulitan untuk mengekspresikan diri ke dalam bahasa.

Memiliki kemampuan dalam berbicara lebih dari 1 bahasa merupakan hal yang dibutuhkan dalam era saat ini terutama diterapkan pada siswa sebagai generasi muda penerus bangsa yang akan bersaing secara global dalam segala sektor baik industri, komunikasi sampai pendidikan.

${ }^{11}$ Santoso and Pirman. 
Penerapan pendidikan dengan menggunakan bilingual berbeda di setiap negara ${ }^{12}$. Negara Indonesia pada tahun 2009 terdapat banyak sekolah yang tidak berhasil dalam menerapkan program bilingual ini. Hal yang menjadi penyebabnya pun beragam mulai dari staf dan guru yang tidak menguasai bilingual, fasilitas sampai materi pembelajaran bilingual sehingga program ini mulai ditinggalkan tanpa adanya perbaikan dari pemerintah.

Glazer and Schmidt menyebutkan beberapa tipe dari program bilingual yang dapat diterapkan dalam pembelajaran bilingual ${ }^{13}$, antara lain:

a. Transitional Bilingual Education (TBI) or early exit model

Dalam program ini, siswa diawal pembelajaran akan diajarkan menggunakan bahasa sehari-hari mereka selanjutnya setelah 3 tahun atau lebih pembelajaran akan diubah meggunakan bahasa Inggris. Penggunaan bahasa sehari-hari mereka diawal pembelajaran bertujuan untuk membantu siswa dalam proses akademik tetapi secara tidak langsung siswa juga belajar bahasa Inggris.

b. Two-Way Bilingual, Two-Way Immersion (TWI) or Paired Bilingual

Program ini sering disebut program bahasa ganda di mana siswa akan mempelajari 2 bahasa sekaligus dalam satu waktu pembelajaran. Pembagian 2 bahasa yang dipelajari bisa disesuaikan pada masingmasing lembaga pendidikan, umumnya dibagi pada waktu harian. Sesi pagi menggunakan satu bahasa, dan di siang harinya menggunakan bahasa yang lain.

c. Language Immersion

Dalam program ini, siswa akan langsung dikelompokkan dan dimasukkan ke dalam kelas bahasa Inggris sehingga disebutlah perendaman bahasa. Menurut program ini, media pembelajaran juga digunakan sebagai objek pengajaran. Setiap siswa yang mengikuti program ini akan memiliki keterampilan yang beragam seperti kemampuan bilingual transisi, program bilingual berpasangan, dll.

d. Submersion or "Sink or Swim"

\footnotetext{
${ }^{12}$ Ima, “Types of Bilingual Education.”

${ }^{13}$ Ima.
} 
Model program ini siswa dengan kemampuan bahasa Inggris yang terbatas tidak menerima bantuan bahasa. Model bilingual ini mengacu pada anak yang berbicara dengan bahasa asing dan mengikuti kelas regular sehingga guru tidak membantu mereka dalam belajar bahasa Inggris.

e. Structured Immersion

Program perendaman terstruktur ini sebagian besar menggunakan bahasa inggris untuk mengajar siswa dengan kemampuan bahasa Inggris yang terbatas. Semua mata pelajaran diajarkan dalam bahasa Inggris, bahasa sehari-hari dan bahasa Inggris dipelajari dan digunakan sesuai dengan tingkat pemahaman materi. Biasanya guru mahir dalam bahasa sehari-hari siswa dan bahasa Inggris sehingga siswa dapat menjawab pertanyaan dalam Bahasa sehari-hari mereka, tetapi guru tetap menjawab dalam bahasa Inggris.

\section{f. English as Second Language (ESL)}

Dalam program ini, siswa kelas regular akan mendapatkan pembelajaran bahasa Inggris tambahan selama dua atau tiga periode sehari tanpa menggunakan pembelajaran dengan bahasa sehari-hari. Pendekatan pembelajaran ini meliputi metode Audio lingual seperti menghafal, meniru dan menyampaikan pelajaran yang sedang diajarkan serta metode komunikasi berbasis bahasa Inggris seperti mengucapkan dengan kalimat sederhana dan isyarat visual untuk menunjukkan pemahaman siswa terhadap suatu pesan dalam bahasa Inggris.

g. Maintenance or Developmental Bilingual Education (DBE)

Program ini dirancang untuk melestarikan dan meningkatkan keterampilan siswa dalam bahasa sehari-hari sementara mereka sedang mempelajari bahasa Inggris. Pembelajaran bahasa asli siswa umumnya dilakukan pada kelas 6. Pembelajaran bahasa tersebut dipertahankan bahkan ketika siswa sudah dianggap mampu dalam berbahasa Inggris. Beberapa ahli menyimpulkan bahwa program ini berfungsi sebagai pendidikan dua arah.

\section{Pendidikan Pesantren}


Pesantren telah berkontribusi dalam pendidikan di Indonesia sejak era penjajahan, dan para ulama atau kyai juga berperan penting dalam pendidikan pesantren ${ }^{14}$. Pesantren juga sebagai subsistem pendidikan nasional karena merupakan salah satu komponen yang menyelenggarakan pendidikan secara nasional. Dalam melaksanakan proses pendidikan, sistem pengajaran dalam pesantren terbagi menjadi dua ${ }^{15}$ antara lain 1) sistem pembelajaran klasik yaitu pengelompokan santri berdasarkan jenjang kelas seperti MTs dan MA, 2) sistem pembelajaran non klasikal yaitu pembelajaran ilmu agama dengan cara yang disebut sorogan yang langsung diajarkan oleh kyai seperti ilmu fiqih, hadits, dll. Pesantren dengan sistem pengajaran tersebut sering dikenal dengan pesantren salaf. Di era globalisasi saat ini eksistensi pesantren salaf yang lebih banyak mempelajari ilmu agama perlu diperhatikan, karena telah disebutkan bahwa pesantren merupakan subsistem pendidikan nasional. Pesantren salaf tetap terjaga eksistensinya di tengah era modern saat ini dikarenakan beberapa hal ${ }^{16}$ yaitu 1) adanya peran kyai yang menentukan kebijakan dalam pesantren, 2) adanya nilai-nilai yang ditanamkan kepada santri dalam pendidikan pesantren, 3) adanya kurikulum untuk mengatur pembelajaran ilmu agama seperti kitab kuning, dan 4) adanya pengabdian kepada pesantren oleh santri yang telah lulus sehingga kualitas pendidikannya akan selalu terjaga. Selain itu, pendidikan dalam pesantren juga memunculkan adanya budaya dalam kehidupan keseharian santri. Pendidikan dalam pesantren memunculkan adanya budaya yang terbentuk seperti budaya disiplin, budaya mandiri, budaya bersih dan rapi serta budaya peduli lingkungan ${ }^{17}$.

14 Suddin Bani, "KONTRIBUSI PESANTREN DALAM SISTEM PENDIDIKAN NASIONAL," Kontribusi Pesantren Dalam Sistem Pendidikan Nasional 2, no. 36 (2015): 264-73.

${ }^{15}$ Kholid Junaidi, "SISTEM PENDIDIKAN PONDOK PESANTREN DI INDONESIA (Suatu Kajian Sistem Kurikulum Di Pondok Pesantren Lirboyo)," ISTAWA: Jurnal Pendidikan Islam 2, no. 2 (2016): 95-110.

${ }^{16}$ Multisitus and Rustam Ibrahim, "EKSISTENSI PESANTREN SALAF DI TENGAH ARUS PENDIDIKAN MODERN The Existence of Salaf Islamic Boarding School amid the Flow of Modern Education (A Multi-Site Study at Pesantren Salafy in Central Java)," no. 1 (2014): 253-63.

${ }_{17}$ M. Syaifuddien Zuhriy, "BUDAYA PESANTREN DAN PENDIDIKAN KARAKTER PADA PONDOK PESANTREN SALAF," Walisongo 19, no. November 2011 (2011): 287-310, https://doi.org/10.15408/mimbar.v0i0.17947. 
Selain pesantren salaf, di Indonesia juga terdapat pesantren modern yang menggabungkan ilmu dalam pesantren salaf dan ilmu umum. Dengan adanya globalisasi yang menyebabkan pendidikan di Indonesia mengalami penyesuaian dalam sistem pendidikannya, terlebih pada pendidikan pesantren. Melalui modernisasi pendidikan pesantren ini diharapkan pesantren tetap menjaga pendidikan ilmu agama walaupun diikuti oleh ilmu umum yang berorientasi pada penguasaan kognitif semata ${ }^{18}$. Dengan tetap berpegang pada pendidikan ilmu agama, pesantren tetap tidak akan kehilangan budaya-budaya santri yang melekat. Munculnya pesantren modern di Indonesia bukan tanpa permasalahan dan kritik, tetapi modernisasi pesantren terbukti membawa banyak dampak positif bagi perkembangan pesantren ${ }^{19}$. Di antaranya munculnya perhatian dan harapan dari masyarakat bahwa pesantren merupakan pendidikan alternatif dengan segala inovasi tanpa menghilangkan karakteristiknya. Tidak sedikit pesantren yang saat ini juga mendirikan sekolah formal. Menurut Wahjoetomo tercatat sebanyak 2.072 pesantren memiliki Madrasah Ibtidaiyah, Madrasah Tsanawiyah sebanyak 2.721 pesantren, Madrasah Aliyah sebanyak 176 pesantren ${ }^{20}$. Jumlah sekolah dibawah naungan pesantren ini menunjukkan bahwa pesantren telah berevolusi menjadi pendidikan yang mengikuti perkembangan modern dengan tetap menanamkan nilai pesantren dalam pendidikan umum atau formal.

Metode penelitian yang digunakan adalah penelitian kajian literatur dengan menelaah 10 jurnal terkait program bilingual dan pendidikan pesantren. Teknik pengumpulan data didapatkan melalui data dari jurnal, artikel ilmiah, textbook, dan literature review. Teknik analisis data dilakukan dengan cara mencari artikel ilmiah yang sesuai dengan materi penelitian, kemudian membaca abstrak dari setiap penelitian, lalu mencatat bagian penting dan relevan dengan permasalahan penelitian. Hasil dari telaah

\footnotetext{
${ }^{18}$ Bashori Bashori, "Modernisasi Lembaga Pendidikan Pesantren," Jurnal Ilmu Sosial Mamangan 6, no. 1 (2017): 47, https://doi.org/10.22202/mamangan.1313.

19 Istikomah Istikomah, "Modernisasi Pesantren Menuju Sekolah Unggul," Halaqa: Islamic Education Journal 1, no. 2 (2017): 53-62, https://doi.org/10.21070/halaqa.v1i2.1246.

${ }^{20}$ Istikomah.
} 
literatur ini digunakan untuk mendeskripsikan implementasi program bilingual pada pendidikan berbasis pesantren sehingga pesantren di Indonesia dapat mengikuti perkembangan globalisasi serta dapat meningkatkan mutu pendidikan Indonesia.

\section{Pembahasan}

Hasil penelitian terkait implementasi program bilingual dalam pendidikan sebagai berikut.

Tabel 3. Implementasi Program Bilingual dalam Pendidikan Indonesia

\begin{tabular}{|c|c|c|}
\hline Penulis & Judul / Tahun & Hasil Penelitian \\
\hline $\begin{array}{l}\text { Makinuddin, } \\
\text { Mohammad }\end{array}$ & $\begin{array}{l}\text { Bahasa Arab Sebagai } \\
\text { Kekhasan Pesantren dan } \\
\text { Tantangannya Dalam } \\
\text { Situasi Global (2017) }\end{array}$ & $\begin{array}{l}\text { Bahasa Arab diajarkan dalam } \\
\text { pesantren yang memiliki hal } \\
\text { penting dalam pembelajaran } \\
\text { didalamnya seperti kitab } \\
\text { kuning yang saat ini sangat } \\
\text { penting bagi eksistensi dan } \\
\text { kompetitif individu di era } \\
\text { globalisasi. Penguasaan } \\
\text { bahasa arab sebagai bahasa } \\
\text { asing dalam pesantren } \\
\text { diharapkan dapat } \\
\text { menghadapi tantangan global } \\
\text { karena bahasa arab dan } \\
\text { pesantren tidak dapat } \\
\text { dipisahkan, oleh karena itu } \\
\text { pesantren menjadi tempat } \\
\text { strategis untuk } \\
\text { mengembangkan bahasa arab. }\end{array}$ \\
\hline $\begin{array}{l}\text { Pransiska, } \\
\text { Rismareni }\end{array}$ & $\begin{array}{l}\text { Kajian Program Bilingual } \\
\text { Terhadap Perkembangan } \\
\text { Kognitif Anak Usia Dini } \\
(2018)\end{array}$ & $\begin{array}{l}\text { Program bilingual memiliki } \\
\text { dampak positif saat } \\
\text { diterapkan di Taman Kanak- } \\
\text { Kanak. Penguasaan program } \\
\text { bilingual membuat } \\
\text { perkembangan kognitif anak } \\
\text { dapat berkembang pesat dan } \\
\text { memiliki perform yang lebih }\end{array}$ \\
\hline
\end{tabular}




\begin{tabular}{|c|c|c|}
\hline & & baik dari monolingual. \\
\hline $\begin{array}{l}\text { Mahmudi dan } \\
\text { Yoga }\end{array}$ & 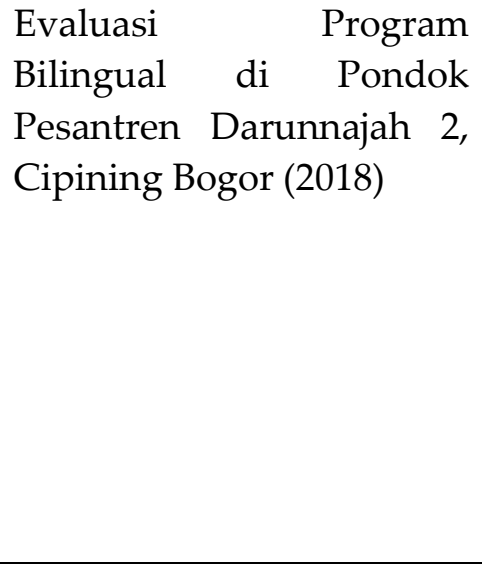 & $\begin{array}{l}\text { Penerapan program bilingual } \\
\text { dalam Pondok Pesantren } \\
\text { Darunnajah } 2 \text { Cipining Bogor } \\
\text { tercapai dengan sangat baik } \\
(75 \%) \text { Evaluasi didapatkan } \\
\text { hasil yang baik dikarenakan } \\
\text { santri memiliki aspek } \\
\text { pengetahuan dan } \\
\text { keterampilan dalam } \\
\text { berbahasa seperti berbicara, } \\
\text { ujian praktek dan lisan. }\end{array}$ \\
\hline $\begin{array}{l}\text { Nugraheni } \\
\text { dan Arina }\end{array}$ & $\begin{array}{lr}\text { Implementasi } & \text { Program } \\
\text { Bilingual Untuk } & \text { Meningkatkan Kecerdasan } \\
\text { Linguistik di SD Intis } \\
\text { School Yogyakarta (2017) }\end{array}$ & $\begin{array}{l}\text { Penerapan program bilingual } \\
\text { yang diterapkan di SD Intis } \\
\text { School Yogyakarta dengan } \\
\text { lima aspek didapatkan hasil } \\
\text { bahwa aspek staff development } \\
\text { dapat membantu tuntutan } \\
\text { komunikasi berbahasa } \\
\text { walapun belum maksimal, } \\
\text { dan aspek curriculum } \\
\text { development } \\
\text { melakukan kegiatan flash card, } \\
\text { market day,dan recitation. }\end{array}$ \\
\hline $\begin{array}{l}\text { Sari dan } \\
\text { Mundilarno }\end{array}$ & $\begin{array}{lr}\text { Penerapan } & \text { Manajemen } \\
\text { Program Kelas } & \text { Bilingual } \\
\text { Cambridge } & \text { Primary } \\
\text { Curriculum } & \text { Framework } \\
(2020) & \end{array}$ & $\begin{array}{l}\text { Penerapan Program Bilingual } \\
\text { dengan kurikulum } \\
\text { Cambridge tergolong baik } \\
\text { yang dilihat dari perencanaan } \\
\text { awal antara pengelola dan } \\
\text { pemimpin sekolah, } \\
\text { pengembangan program, } \\
\text { pelaksanaan perencanaan, } \\
\text { serta evaluasi yang berjalan } \\
\text { secara sistematis dan } \\
\text { berkesinambungan. Program } \\
\text { Bilingual dengan kurikulum } \\
\text { Cambridge mendapat } \\
\text { apresiasi yang baik dari }\end{array}$ \\
\hline
\end{tabular}




\begin{tabular}{|c|c|c|}
\hline & & $\begin{array}{l}\text { sekolah, wali murid, murid, } \\
\text { dan masyarakat. }\end{array}$ \\
\hline $\begin{array}{l}\text { 'Aini, } \\
\text { Zahrotul }\end{array}$ & $\begin{array}{lr}\text { Implementasi } & \text { Program } \\
\text { Bilingual } & \text { untuk } \\
\text { Meningkatkan } & \\
\text { Keterampilan } & \text { Bahasa } \\
\text { Inggris Siswa di } & \text { Madrasah } \\
\text { Ibtidaiyah } & \text { Khadijah } \\
\text { Malang (2013) } & \end{array}$ & $\begin{array}{l}\text { Program bilingual } \\
\text { diimplementasikan dengan } \\
\text { mengacu pada kurikulum SD } \\
\text { disesuaikan dengan } \\
\text { kebutuhan siswa dan hasilnya } \\
\text { terdapat peningkatan } \\
\text { keterampilan bahasa inggris } \\
\text { siswa yang cukup baik. Hal } \\
\text { tersebut dikarenakan motivasi } \\
\text { siswa yang tinggi, sarana } \\
\text { prasarana yang memadai dan } \\
\text { kompetensi linguistik siswa } \\
\text { yang baik. }\end{array}$ \\
\hline $\begin{array}{l}\text { Dewanti, } \\
\text { Artika }\end{array}$ & $\begin{array}{l}\text { The Role of Bilingual } \\
\text { Program at Pondok } \\
\text { Pesantren Modern (Modern } \\
\text { Boarding School) in } \\
\text { Developing English Skills of } \\
\text { Santri(2015) }\end{array}$ & $\begin{array}{l}\text { Program bilingual di } \\
\text { Muhammadiyah Boarding } \\
\text { School Yogyakarta adalah } \\
\text { sebagai fasilitator dan sebagai } \\
\text { instrument dalam } \\
\text { mengembangkan kecakapan } \\
\text { berbahasa Inggris santri. } \\
\text { Sebagai sebuah fasilitator dan } \\
\text { instrument, peran utama } \\
\text { program bilingual tersebut } \\
\text { adalah untuk membantu dan } \\
\text { mempersiapkan santri agar } \\
\text { mampu berkomunikasi secara } \\
\text { aktif dengan menggunakan } \\
\text { bahasa Inggris. }\end{array}$ \\
\hline $\begin{array}{l}\text { Nisa', } \\
\text { Khoirun }\end{array}$ & \begin{tabular}{lrr} 
Manajemen & \multicolumn{2}{c}{ Kurikulum } \\
Pondok Pesantren & dalam \\
Membina Santri & Yang \\
Memiliki Daya & Saing \\
Tinggi (2020) &
\end{tabular} & $\begin{array}{lrr}\text { Program } & \text { bilingual } & \text { dalam } \\
\text { membina } & \text { santri } & \text { yang } \\
\text { memiliki daya saing tinggi } & \text { tingi } \\
\text { Pondok Pesantren } & \text { Assalafi } \\
\text { Miftahul Huda } & \text { Ngroto } \\
\text { memiliki tiga program yang } \\
\text { menunjang } & \text { proses } \\
\text { berjalannya } & \text { program }\end{array}$ \\
\hline
\end{tabular}




\begin{tabular}{|c|c|c|}
\hline & & bilingual \\
\hline Jauhari & $\begin{array}{l}\text { The Implementation Of } \\
\text { Language Program Towards } \\
\text { Students' Foreign Language } \\
\text { Acquisition At Bilingual } \\
\text { Islamic Boarding School Of } \\
\text { Darul Amien Academic Year } \\
\text { 2016/2017 (2017) }\end{array}$ & $\begin{array}{l}\text { Pelaksanaan program bahasa } \\
\text { terhadap pemerolehan bahasa } \\
\text { asing dan kesulitan bagian } \\
\text { bahasa dalam pelaksanaan } \\
\text { program bahasa pemerolehan } \\
\text { bahasa asing 1) Ada dua jenis } \\
\text { program bahasa; yaitu } \\
\text { program bahasa harian dan } \\
\text { program mingguan. Program } \\
\text { bahasa harian yaitu program } \\
\text { dimana para santri belajar } \\
\text { dan praktek bahasa asing } \\
\text { sehari-sehari. Ada lima } \\
\text { aktifitas yang terdiri dari hari } \\
\text { bahasa inggris, pengayaan } \\
\text { kosa kata bahasa asing, } \\
\text { latihan kalimat, percakapan } \\
\text { bahasa inggris dan } \\
\text { pengumuman. }\end{array}$ \\
\hline $\begin{array}{l}\text { Mansyur dan } \\
\text { Rofiqi }\end{array}$ & $\begin{array}{l}\text { Implementasi Pengelolaan } \\
\text { Bilingual Area Ramah } \\
\text { Anak (2019) }\end{array}$ & $\begin{array}{lr}\text { Pelaksanaan } & \text { Kegiatan } \\
\text { Bilingual Area di Madrasah } \\
\text { Ummul Quro } & \text { At- } \\
\text { Tarbawiyah dibagi } & \text { menjadi } \\
\text { satu minggu untuk } & \text { Bahasa } \\
\text { Arab dan satu } & \text { minggu } \\
\text { berikutnya untuk } & \text { Bahasa } \\
\text { Inggris. Hasil } & \text { dari } \\
\text { pelaksanaan } & \text { Kegiatan } \\
\text { Bilingual Area di } & \text { Madrasah } \\
\text { Ummul Quro } & \text { At- } \\
\text { Tarbawiyah sudah cukup } \\
\text { baik, siswa di madrasah ini } \\
\text { sudah bisa berkomunikasi } \\
\text { dengan teman sejawatnya } \\
\text { beserta } \\
\text { menggunakan } 2 & \text { garu-guru } \\
\text { walaupun ini, } & \text { di sana-sini }\end{array}$ \\
\hline
\end{tabular}




\begin{tabular}{|l|l|l|}
\hline & $\begin{array}{l}\text { masih membutuhkan } \\
\text { latihan dan bimbingan lagi }\end{array}$ \\
\hline
\end{tabular}

Berdasarkan tabel di atas, dapat disimpulkan bahwa program bilingual memberikan dampak yang positif dan dapat meningkatkan daya kompetitif dalam pendidikan Indonesia khususnya dalam pondok pesantren dengan memperhatikan kurikulum Indonesia dan tidak meninggalkan budaya pesantren. Melalui implementasi program bilingual di pesantren diharapkan santri dapat bersaing di kancah internasional.

Semakin bertambahnya pesantren yang mengadakan pendidikan formal selain ilmu agama yang diajarkan, membuat pesantren telah dipercaya oleh banyak masyarakat untuk menitipkan anak menuntut ilmu di lembaga pesantren. Pernyataan tersebut mendukung suatu penelitian dengan hasil bahwa dalam 5 tahun terakhir siswa yang mendaftar ke sekolah tersebut

mengalami peningkatan ${ }^{21}$.

\begin{tabular}{cccc} 
No. & Tahun pelajaran & Pendaftar & Diterima \\
\hline 1 & $2011 / 2012$ & 250 & 164 \\
2 & 20122013 & 255 & 198 \\
3 & $2013 / 2014$ & 260 & 229 \\
4 & $2014 / 2015$ & 270 & 228 \\
5 & $2015 / 2016$ & 302 & 233
\end{tabular}

Sumber : Saepudin (2019)

Gambar 1. Tabel peningkatan jumlah siswa di SMP Al-Muttaqin sekolah berbasis pesantren

Dalam pesantren yang memiliki lembaga formal pun, juga menerapkan kurikulum 2013 yang didesain pula untuk mata pelajaran agama yang didalamnya sesuai dengan peraturan kemenag. Implementasi kurikulum 2013 dalam sekolah berbasis pesantren menghasilkan suatu desain

${ }^{21}$ Juju Saepudin, "Pendidikan Agama Islam Pada Sekolah Berbasis Pesantren: Studi Kasus Pada SMP Al Muttaqin Kota Tasikmalaya," EDUKASI: Jurnal Penelitian Pendidikan Agama Dan Keagamaan 17, no. 2 (2019): 172-87, https://doi.org/10.32729/edukasi.v17i2.559. 
kurikulum yang unik yaitu perpaduan antara kurikulum 2013, kemenag dan karakteristik pesantren ${ }^{22}$. Hal tersebut tentunya sangat membantu dalam ketercapaian kurikulum 2013 dengan salah satu aspek penilaiannya yaitu aspek sikap dan perilaku peserta didik.

Lembaga formal dalam pesantren pun telah menunjukkan sisi modern dalam kurikulum serta pembelajarannya dengan tidak meninggalkan karakteristiknya. Begitu pula dengan pesantren modern yang di dalam pengajarannya menerapkan bilingual atau dua bahasa sebagai wujud pendidikan pesantren yang modern dan mengikuti perkembangan era demi mewujudkan cita-cita pendidikan nasional. Adanya pesantren modern di Indonesia diharapkan pendidikan pesantren dapat menjadikan siswa atau santri siap berkontribusi pada negara dalam membangun peradaban di era globalisasi yang semakin mendunia ${ }^{23}$. Dalam pesantren modern ini, siswa atau santri menggunakan bahasa Arab dan Inggris dalam kehidupan seharihari dalam lingkungan pesantren, tidak hanya itu pembelajaran juga dilaksanakan menggunakan bahasa Arab dan Inggris. Bahasa Arab juga merupakan suatu bahasa yang sering digunakan dalam pembelajaran dalam pesantren yang memiliki daya saing di era global yang berkedudukan sebagai bahasa internasional sehingga perlunya santri atau siswa juga menguasai bahasa $\operatorname{arab}^{24}$.

Penggunaan program bilingual ini tidak hanya berguna sebagai persaingan global dalam segala sektor tetapi lebih dari itu, program bilingual mampu digunakan untuk meningkatkan kecerdasan linguistik. Pernyataan tersebut mendukung suatu hasil penelitian bahwa programprogram pengembangan yang ada di SD Intis School Yogyakarta telah membantu untuk memenuhi tuntutan keterampilan komunikasi berbahasa

${ }^{22}$ Joko Paminto et al., "Implementasi Kurikulum 2013 Di Sekolah Pesantren Dengan Sistem Boarding School," Indonesian Journal of Curriculum and Educational Technology Studies 6, no. 1 (2018): 41-52, https://doi.org/10.15294/ijcets.v6i1.15937.

${ }^{23}$ Abdul Tolib, "PENDIDIKAN DI PONDOK PESANTREN MODERN Oleh: Dr. Abdul Tolib," Jurnal Risaalah 1, no. 1 (2015): 60-66, http:/jurnal.faiunwir.ac.id.

${ }^{24}$ Mohammad Makinuddin, "Bahasa Arab Sebagai Kekhasan Pesantren Dan Tantangannya Dalam Situasi Global," Journal of Applied Linguistics and Islamic Education 01, no. 1 (2017): 288-308. 
inggris siswa. Dalam penerapan program bilingual ini, terdapat beberapa program sekolah untuk meningkatkan komunikasi dalam bahasa Inggris siswa, antara lain flash card, kultum berbahasa inggria, Hunting touriat, market day dan English day ${ }^{25}$.

Selain itu, hal terpenting dengan adanya program bilingual yaitu dapat meningkatkan mutu pendidikan. Hal tersebut mendukung suatu hasil penelitian yaitu bahwa program bilingual dengan kurikulum Cambridge mendapat apresiasi yang baik dari sekolah, wali murid, murid, dan masyarakat ${ }^{26}$. Dari penelitian yang dilakukan disimpulkan bahwa penerapan program bilingual dengan kurikulum Cambridge tergolong baik yang ditunjukkan dari perencanaan awal antara pengelola dan pemimpin sekolah, pengembangan program, pelaksanaan perencanaan, serta evaluasi yang berjalan secara sistematis dan berkesinambungan.

Implementasi program bilingual yang diterapkan di pesantren telah dibuktikan mampu mencapai kategori baik yang artinya dengan adanya program bilingual mampu meningkatkan kemampuan bilingual siswa atau santri yang akan bermanfaat dalam jenjang pendidikan yang lebih tinggi atau menghadapi persaingan global. Penelitian tersebut telah dilakukan dengan hasil sebagai berikut ${ }^{27}$.

${ }_{25}$ Aninditya Sri Nugraheni, "Implementasi Program Bilingual School Untuk Meningkatkan Kecerdasan Linguistik Di SD INTIS School Yogyakarta," Jurnal Pendidikan Dan Pembelajaran Dasar 4, no. 1 (2017): 83-84.

${ }^{26}$ Dewi Paramita Sari, "Penerapan Manajemen Program Kelas Bilingual Cambridge Primary Curriculum Framework," Media Manajemen Pendidikan 2, no. 3 (2020): 419, https://doi.org/10.30738/mmp.v2i3.6785.

27 Ihwan Mahmudi and Yoga Saputra, "Evaluasi Program Pembelajara Bilingual Di Pondok Pesantren Darunnajah 2, Cipinang Bogor," Jurnal At-Ta'dib 13, no. 2 (2018): 62. 


\begin{tabular}{|c|c|c|c|}
\hline No & Aspek yang dievaluasi & Ya & Tidak \\
\hline 1 & Aspek Pengetahuan dalam berbahasa & $\sqrt{ }$ & \\
\hline 2 & Aspek Keterampilan Berbahasa & $\sqrt{ }$ & \\
\hline 3 & Aspek pencapaian dalam berbahasa & & $\mathrm{X}$ \\
\hline 4 & Aspek Prestasi dalam berbahasa & $\sqrt{ }$ & \\
\hline
\end{tabular}

Sumber: Mahmudi dan Yogi (2018)

Gambar 2. Tabel Aspek Pengetahuan Kemampuan Santri

Dalam aspek pengetahuan ditunjukkan dari kemampuan santri dalam melaksanakan ujian lisan dan tulis, untuk aspek keterampilan ditunjukkan melalui keterampilan siswa dalam berbicara, membaca, menyimak percakapan sehari-hari dengan teman, dan aspek prestasi ditunjukkan dengan keikutsertaan santri dalam perlombaan pidato dengan bilingual, dan menonton video berbahasa arab dengan diakhiri kuis mengenai video tersebut untuk menilai bahwa santri faham isi video tersebut.

Pendidikan dalam pesantren saat ini tidak bisa dikesampingkan, pesantren sebagai bagian dari sistem pendidikan di Indonesia mampu membuat perubahan sosial seperti banyaknya siswa yang berprestasi, nilai ujian nasional yang tinggi, keberhasilan siswa diterima di universitas, serta nilai-nilai agama yang ada pada individu siswa. Penyebab adanya perubahan social dalam sekolah berbasis pesantren yaitu komunikasi antar lembaga seperti kemenag, kemendikbud, pesantren dan sekolah serta lembaga lain yang berwenang dalam pengembangan sekolah ${ }^{28}$. Oleh karena itu pentingnya sinergi antara beberapa pihak untuk mewujudkan mutu pendidikan Indonesia lebih baik. Selain itu, pesantren sebagai lembaga yang khas dan mandiri berprinsip "dari masyarakat, oleh masyarakat dan untuk masyarakat" artinya bahwa setiap siswa atau santri berasal dari lingkungan masyarakat, yang didukung oleh masyarakat sekitar pesantren

\footnotetext{
${ }^{28}$ Nurochim Nurochim, "Sekolah Berbasis Pesantren Sebagai Salah Satu Model Pendidikan Islam Dalam Konsepsi Perubahan Sosial," Al-Tahrir: Jurnal Pemikiran Islam 16, no. 1 (2016): 69, https://doi.org/10.21154/al-tahrir.v16i1.320.
} 
untuk nantinya siap berkontribusi kepada masyarakat menjadi generasi muda penerus bangsa yang lebih maju ${ }^{29}$.

\section{Kesimpulan}

Berdasarkan uraian di atas dapat disimpulkan bahwa: 1) Pesantren sebagai bagian dari sistem pendidikan Nasional diharapkan turut membangun tujuan pendidikan Indonesia dengan mengikuti perkembangan era globalisasi, 2) Pesantren berpotensi sebagai sistem pendidikan nasional yang mampu mengikuti perkembangan zaman dan bersaing secara global dengan menerapkan program bilingual pada proses pembelajaran, 3) Dengan adanya modernisasi pesantren tidak mengubah karakteristik pesantren sebagai lembaga pendidikan yang berpegang pada ilmu agama Islam, 4) Program bilingual dapat dengan baik diterapkan di pesantren karena dapat meningkatkan mutu pendidikan yang sesuai dengan harapan para orangtua.

\section{Daftar Pustaka}

'Aini, Z. (2013). IMPLEMENTASI PROGRAM BILINGUAL UNTUK

\section{MENINGKATKAN KETERAMPILAN BAHASA INGGRIS}

IMPLEMENTASI PROGRAM BILINGUAL UNTUK. Universitas Islam

Negeri Maulana Malik Ibrahim Malang.

Alhamuddin. "Sejarah Kurikulum di Indonesia." Nur El-Islam 1, no. 2 (2014): 48-58.

Bani, Suddin. "Kontribusi Pesantren dalam Sistem Pendidikan Nasional." Kontribusi Pesantren Dalam Sistem Pendidikan Nasional 2, no. 36 (2015): 264-73.

\footnotetext{
${ }^{29}$ Ulfah Rahmawati, "Pesantren: Lembaga Pendidikan Berbasis Masyarakat (Tinjauan Pasal 1 Ayat 4 PP Nomor 55 T Ahun 2007 Tentang Pendidikan Agama Dan Pendidikan Keagamaan)," Jurnal Penelitian 11, no. 2 (2018): 443-66, https://doi.org/10.21043/jupe.v11i2.3490.
} 
Bashori, Bashori. “Modernisasi Lembaga Pendidikan Pesantren.” Jurnal Ilmu Sosial Mamangan 6, no. 1 (2017): 47. https://doi.org/10.22202/mamangan.1313

Dewanti, A. (2015). The Role of Bilingual Program at Pondok Pesantren Modern (Modern Boarding School) in Developing English Skills of Santri (A Descriptive Qualitative Study in Muhammadiyah Boarding School Yogyakarta in the 2015/2016 Academic Year). Universitas Negeri Surakarta.

Hasan, Mohammad. "Perkembangan Pendidikan Pesantren di Indonesia." TADRIS: Jurnal Pendidikan Islam 10, no. 1 (2015): 55. https://doi.org/10.19105/jpi.v10i1.638.

Ima, Dwi. “Types of Bilingual Education." Bahasa Lingua Scientia 5, no. 2 (2013): 212-26.

Istikomah, Istikomah. "Modernisasi Pesantren Menuju Sekolah Unggul." Halaqa: Islamic Education Journal 1, no. 2 (2017): 53-62. https://doi.org/10.21070/halaqa.v1i2.1246.

Jauhari. (2017). The Implementation of Language Program towards

Students' Foreign Language Acquisition at Bilingual Islamic Boarding School of Darul Amien Academic Year 2016/2017. 1-67.

Junaidi, Kholid. “Sistem Pendidikan Pondok Pesantren di Indonesia (Suatu Kajian Sistem Kurikulum Di Pondok Pesantren Lirboyo)." ISTAWA: Jurnal Pendidikan Islam 2, no. 2 (2016): 95-110.

Kemdiknas, B. (2006). Kajian Terhadap Keberadaan dan Pendanaan Rintisan Sekolah Bertaraf Internasional ( RSBI ). Jurnal Dikbud, 373-382. 
Mahmudi, Ihwan, and Yoga Saputra. “Evaluasi Program Pembelajara Bilingual di Pondok Pesantren Darunnajah 2, Cipinang Bogor." Jurnal At-Ta'dib 13, no. 2 (2018): 62.

Makinuddin, Mohammad. "Bahasa Arab Sebagai Kekhasan Pesantren dan Tantangannya Dalam Situasi Global." Journal of Applied Linguistics and Islamic Education 01, no. 1 (2017): 288-308.

Mansyur, M., \& Rofiqi. (2019). Implementasi Pengelolaan Bilingual Area Ramah Anak. Muhadasah: Jurnal Pendidikan Bahasa Arab, 2, 51-58. Multisitus, and Rustam Ibrahim. "Eksistensi Pesantren Salaf di Tengah Arus Pendidikan Modern The Existence of Salaf Islamic Boarding School amid the Flow of Modern Education (A Multi-Site Study at Pesantren Salafy in Central Java)," no. 1 (2014): 253-63.

Nisa', K. (2020). Manajemen Kurikulum Pondok Pesantren Dalam Membina Santri Yang Memiliki Daya Saing Tinggi (Studi Kasus Pondok Pesantren Assalafi Miftahul Huda Ngroto Gubug Grobogan Jawa Tengah). 1-139.

Nugraheni, Aninditya Sri. "Implementasi Program Bilingual School untuk Meningkatkan Kecerdasan Linguistik di SD INTIS School Yogyakarta." Jurnal Pendidikan Dan Pembelajaran Dasar 4, no. 1 (2017): 83-84.

Nurochim, Nurochim. "Sekolah Berbasis Pesantren Sebagai Salah Satu Model Pendidikan Islam dalam Konsepsi Perubahan Sosial." AlTahrir: Jurnal Pemikiran Islam 16, no. 1 (2016): 69. https://doi.org/10.21154/al-tahrir.v16i1.320.

Paminto, Joko, Tina Rosiana, Budiyono Budiyono, and Heri Triluqman Budisantoso. “Implementasi Kurikulum 2013 di Sekolah 
Pesantren Dengan Sistem Boarding School." Indonesian Journal of Curriculum and Educational Technology Studies 6, no. 1 (2018): 4152. https://doi.org/10.15294/ijcets.v6i1.15937.

Pransiska, Rismareni. “Kajian Program Bilingual Terhadap Perkembangan Kognitif Anak Usia Dini." Edukasi Journal 10, no. 2 (2018): 167-78. https://doi.org/10.31603/edukasi.v10i2.2409.

PS, Alaika M Bagus Kurnia. “Problematika Pesantren Sebagai Lembaga Pendidikan Islam di Indonesia." Tawazun: Jurnal Pendidikan Islam 12, no. 2 (2019): 5-10. https://doi.org/10.32832/tawazun.v12i2.2554.

Rahmawati, Ulfah. “Pesantren: Lembaga Pendidikan Berbasis Masyarakat (Tinjauan Pasal 1 Ayat 4 PP Nomor 55 T Ahun 2007 Tentang Pendidikan Agama Dan Pendidikan Keagamaan)." Jurnal Penelitian 11, no. 2 (2018): 443-66. https://doi.org/10.21043/jupe.v11i2.3490.

Roberts, Cheryl A. “Bilingual Education Program Models: A Framework for Understanding." Bilingual Research Journal 19, no. 3-4 (1995): 36978. https://doi.org/10.1080/15235882.1995.10162679.

Saepudin, Juju. "Pendidikan Agama Islam Pada Sekolah Berbasis Pesantren: Studi Kasus Pada SMP Al Muttaqin Kota Tasikmalaya." EDUKASI: Jurnal Penelitian Pendidikan Agama Dan Keagamaan 17, no. 2 (2019): 172-87. https://doi.org/10.32729/edukasi.v17i2.559.

Santoso, and Pirman. Bilingual Education Program. Jakarta: Prenadamedia Group, 2015.

Sari, Dewi Paramita. “Penerapan Manajemen Program Kelas Bilingual Cambridge Primary Curriculum Framework." Media Manajemen 
$\begin{array}{llllll}\text { Pendidikan } & 2, & \text { no. } & 3 & \text { (2020): } & 419 .\end{array}$ https://doi.org/10.30738/mmp.v2i3.6785.

Syafe'i, Imam. “Pondok Pesantren Yang Melembaga di Masyaraka Satu Lembaga Pendidikan Islam Tertua Di Indonesia . Awal Kehadiran Boarding School Bersifat Tradisional Untuk Mendalami IlmuIlmu Agama Isl." Al-Tadzkiyyah: Jurnal Pendidikan Islam 8, no. I (2017): 61-82.

Tolib, Abdul. "Pendidikan di Pondok Pesantren Modern." Jurnal Risaalah 1, no. 1 (2015): 60-66. http:/jurnal.faiunwir.ac.id.

Zuhriy, M. Syaifuddien. “Budaya Pesantren dan Pendidikan Karakter Pada Pondok Pesantren Salaf." Walisongo 19, no. November 2011 (2011): 287-310. https://doi.org/10.15408/mimbar.v0i0.17947. 